\title{
Educação infantil e PNE: questões e tensões para o século XXI
}

\author{
Solange Estanislau dos Santos*
}

Faria, Ana Lúcia Goulart de; Aquino, Ligia Maria Leão (Org.). Educação infantil e PNE: questões e tensões para o século XXI. Campinas: Autores Associados, 2012, 102p. (Coleção Formação de Professores).

Este livro, lançado em 2012 na 35aㅡ Reunião Anual da Associação Nacional de Pesquisa e Pós-Graduação em Educação (ANPED), pela editora Autores Associados, coloca-nos novamente diante da metáfora do mito de Sísifo². E nos permite questionar: "estamos vivendo um período de queda? Tal como Sísifo, vive-se agora uma repetição da experiência: [...]; perdeu-se a memória do passado recente e reinventam-se modelos já reprovados" (Rosemberg, 2003, p. 177).

Dez anos depois, é essa mesma impressão que nos causam os fatos recentes, alvos do debate dos artigos organizados e apresentados por Ana Lúcia Goulart de Faria, professora da Universidade Estadual de Campinas e da
* Faculdade de Educação, Universidade Estadual de Campinas (Unicamp), Campinas, SP, Brasil. solestani13@yahoo.com.br

Universitá degli Studi di Milano-Bicocca, Bicocca/Itália, e Ligia Maria Leão de Aquino, professora da Universidade do Estado do Rio de Janeiro, ambas pesquisadoras de temas relacionados à criança pequena e militantes em favor da infância e da Educação Infantil pública, gratuita, laica, de qualidade, que considere a criança como centro do processo educativo. "A centralidade da criança pequena nas políticas públicas da educação infantil era e continua sendo nossa utopia, não a abandonamos!!!!” (Faria; Aquino, 2012, p. 2-3).

O livro problematiza as questões e as tensões que rondam a elaboração e a aprovação do Plano Nacional de Educação - PNE (2011-2020). Inclui também, anexo, o "Manifesto Indignado do Fórum

1. Dez anos atrás, Fúlvia Rosemberg publicou um artigo que comparava as políticas públicas para a Educação Infantil com o mito de Sísifo. Este faz parte da mitologia grega e consiste numa punição dos deuses para um camponês, Sísifo, que ousou traí-los. 0 castigo era rolar diariamente uma pedra montanha acima até o topo. Quando chegava ao topo, ela rolava para baixo, obrigando-o a fazer todo o trabalho novamente, para sempre. 
Paulista de Educação Infantil (FPEI): avaliar para quê? E para quem?", construído pelo grupo gestor do Fórum, aponta argumentos contrários a avaliações que hierarquizam, segregam e excluem as crianças, e reforça: "Não admitimos que uma avaliação que não serve para as crianças do ensino fundamental [...] seja estendida à educação infantil" (FPEl, 2012, p. 8).

No prefácio, Maria Letícia Barros Pedroso Nascimento já nos antecipa que as discussões e as iniciativas em torno do PNE (2011-2020) "causam espanto e provocam um repensar sobre os valores e significados atribuídos à primeira etapa da educação nacional" (Nascimento, 2012, p. viii).

Roselane Fátima Campos e Rosânia Campos apontam que as perspectivas não são nada alentadoras. No texto "Políticas para a educação infantil e os desafios do novo Plano Nacional de Educação: similitudes e divergência entre as experiências brasileira e de outros países latino-americanos", apresentam indicadores das políticas educativas para a Educação Infantil na América Latina e comparam-nas com as propostas trazidas pelo PNE (2011-2020). Dentre as várias preocupações apontadas, vale destacar a que se refere à obrigatoriedade da educação a partir dos 4 anos de idade, o que já parece indicar, no pró- prio PNE, a omissão do poder público e a possivel escassez de oferta de educação para as crianças de o a 3 anos, o que o "afasta da lógica da educação como direito e bem público universal" (Campos; Campos, 2012, p. 23). No geral, as autoras avaliam que o PNE não indica avanços para a educação da criança de o a 3 anos de idade: traz a visão da educação compensatória como remédio para a pobreza e reforça a segmentação do atendimento na Educação Infantil. São, portanto, retrocessos que dificultam "a luta pela definição de uma política articulada para a área" (Campos; Campos, 2012, p. 27).

No texto intitulado "Por uma política para educação da pequena infância que garanta interação entre elas: a relação criança-criança nos Indicadores de Qualidade na Educação Infantil”, Fabiana Oliveira Canavieira problematiza a forma como as interações entre as crianças estão sendo consideradas pelas políticas educativas, mais especificamente, no documento "Indicadores de Qualidade na Educação Infantil” (Brasil, 2009) e no PNE (2011-2020). Constata que tais políticas, fundamentadas no adultocentrismo, não dão "centralidade às próprias crianças em seu processo educativo" (Canavieira, 2012, p. 32). Finaliza, indicando que o PNE deveria ser uma política propositiva, ao invés de tornar-se 
uma grande “'carta de intenções', que no âmbito da educação infantil reedita o passado (PNE 2001-2010) e não modifica o futuro".

Peterson Rigato da Silva e Viviane Drumond, no terceiro texto, “A educação infantil no contexto do PNE: a unidade na educação das crianças de o a 6 anos", retomam alguns pontos da legislação brasileira que garantiu os direitos das crianças à educação em espaços coletivos e públicos. E alerta que tais avanços já estariam sendo ameaçados pela emenda constitucional n.59/2009, que trata da obrigatoriedade de matrícula e frequência das crianças de 4 e 5 anos na pré-escola; e ameaçados também com a aprovação do ensino de nove anos (lei n. 11.114, de 2005), já que tal antecipação da escolarização anteciparia também a exclusão, tendo em vista as fragilidades, as carências e as crueldades do sistema escolar. Ameaças também presentes em algumas proposições do novo PNE: a privatização das creches, que acarreta a desresponsabilização do Estado; a avaliação das instituições, o que pode motivar testes para as crianças; a formação de professoras/es para creches e educação especial fora dos cursos de Pedagogia, que indica falta de propostas e um recuo da profissionalização. E todo esse retrocesso culminaria na "perda da identidade da educação infantil e na hie- rarquização entre as etapas [...]- creche e pré-escola. $O$ novo PNE está defendendo os interesses de quem?" (Silva; Drumond, 2012, p. 58).

No quarto texto, "Questões curriculares para educação infantil e PNE”, Ligia Maria Leão de Aquino e Vera Maria R. de Vasconcellos afirmam que alguns avanços na legislação educacional garantiram visibilidade às crianças e foram resultados das lutas e das reivindicações da população, dos movimentos sociais e de entidades de pesquisa, especialmente da ANPED. Ao partirem da concepção de currículo como artefato cultural e social, as autoras indicam os avanços das $\mathrm{DCNEI} / 2009^{2}$, que propõem um "planejamento a partir das experiências e dos interesses das crianças, de seus grupos de origem e da sociedade brasileira" (Aquino; Vasconcellos, 2012, p.75). E criticam o novo PNE (2011-2020), que faz referência genérica e imprecisa ao caráter heterogêneo da infância e traz "embutido um modelo de formação para a conformação/adequação a um mundo produtivista e consumista" (Aquino; Vasconcellos, 2012, p.79).

No quinto texto, "O Plano Nacional de Educação e a normatização da infância”, Anete Abramowicz, Tatiane Cosentino Rodrigues e Andrea Braga Moruzzi,

2. Diretrizes Curriculares Nacionais para a Educação Infantil (Brasil, 2009). 
ao conceituarem a infância como construção social e "invenção territorializada na modernidade", produzida de várias formas, dentre elas as normatizações jurídicas, questionam: o que seria uma "infância normatizada”? Afirmam a infância como um dispositivo ${ }^{3}$ de poder e reconhecem também que o PNE traz diversas disposições que irão normatizar a vida das crianças e determinar-lhes uma infância. Mas qual seria essa infância? E para qual criança? As autoras avaliam que o PNE anterior (2001-2010) revelava uma "concepção desenvolvimentista de criança e infância e considerava a educação infantil como um momento fundamental de 'investimento' no desenvolvimento da criança”. E que há desigualdade de ingresso na Educação Infantil, sendo as crianças pobres e negras excluídas do acesso às creches e pré-escolas, o que leva a avaliar que "a política educacional para as crianças pequenas continua sendo restrita, seletiva e racista, mesmo em tempos de afirmação da diversidade como um valor que orienta as políticas nacionais de educação" (Abramowicz; Rodrigues; Moruzzi,
2012, p. 96). Parece não haver mudanças no novo PNE (2011-2020), o qual atende parcialmente as indicações da CONAE4, “avança pouco e não demonstra nenhum rompimento com as concepções anteriores de infância e criança, [...] e compreende a educação infantil como investimento com retorno garantido a ser aferido no IDEB5" (Abramowicz; Rodrigues; Moruzzi, 2012, p. 99).

O livro apresenta importantes contribuições e argumentações consistentes que, nesse momento, são instrumentos de luta para evitar que a Educação Infantil continue tendo o mito de Sísifo como metáfora. Traz "ainda algum otimismo e fôlego para continuarmos, seja denunciando perdas, seja revelando utopias, sempre alertando para as armadilhas" (Faria; Aquino, 2012, p. 2-3). E se apresenta como um grito de indignação e resistência, proferido veementemente pelas organizadoras na Apresentação: "Continuamos na militância, agora, principalmente, vigilantes contra o retrocesso, insistindo, pelo menos, na manutenção daquilo que já conquistamos" (Faria; Aquino, 2012, p. 2).

3. As autoras usam o conceito de "dispositivo" de Foucault. Para ele, o dispositivo é "o conceito que ajuda a compreender os diferentes modos de produção dos acordos contratuais [...]" (Abramowicz; Rodrigues; Moruzzi, 2012, p. 85).

4. Conferência Nacional de Educação realizada em Brasília, de 28 de março a 1을 de abril de 2010. 〈http://conae.mec.gov.br/.

5. 0 Índice de Desenvolvimento da Educação Básica. 


\section{Referências Bibliográficas}

BRASIL. Diretrizes Curriculares Nacionais para a Educação Infantil. Brasília: MEC, SEB, 2009.

BRASIL. Emenda constitucional n.59, de 11 de novembro de 2009. Disponível em: http://www.planalto.gov.br/ccivil_03/ constituicao/emendas/emc/emc59. htm. Acesso em: jun./2013.

BRASIL. Lei n. 11.114, de 16 de maio de 2005. Torna obrigatório o Ensino Fundamental aos seis anos de idade. Disponivel em: 〈http://www.planalto.gov. br/ccivil_03/_At02004-2006/2005/Lei/ L11114.htm>. Acesso em: jun. 2013.

ROSEMBERG, F. Sísifo e a educação infantil brasileira. Pro-Posições, Campinas, v. 14, n. 1 (40), p.177-194, jan./abr. 2003. 
248 